\title{
AS (NOVAS) DIRETRIZES CURRICULARES NACIONAIS DA EDUCAÇÃO FÍSICA: A FRAGMENTAÇÃO REPAGINADA
}

\author{
LAS (NUEVAS) DIRECTRICES DE LA EDUCACIÓN FÍSICA: LA FRAGMENTACIÓN \\ REPAGINADA
}

\section{THE (NEW) OF THE PHYSICAL EDUCATION CURRICULUM GUIDELINES: REMODELED FRAGMENTATION}

DOI: http://dx.doi.org/10.9771/gmed.v11i3.34754

\author{
Osvaldo Galdino dos Santos Júnior ${ }^{1}$ \\ Robson dos Santos Bastos ${ }^{2}$
}

\begin{abstract}
Resumo: Objetivando analisar a fragmentação da formação nas (novas) Diretrizes Curriculares Nacionais dos cursos de graduação em Educação Física (Resolução CNE/CES nº 06/2018), o estudo se utiliza da análise documental para revelar os debates que antecederam sua publicação e a concepção de formação nelas presente. Constatamos que a fragmentação foi repaginada, se mantém na lógica destrutiva do capital, assim como a concepção de formação contínua direcionada à instrumentalização para o trabalho.

Palavras-chave: Formação de Professores. Diretrizes Curriculares Nacionais. Educação Física.
\end{abstract}

Resumen: Con el objetivo de analizar la fragmentación de la formación en las (nuevas) Directrices Curriculares Nacionales de los cursos de graduación en Educación Física (Resolución CNE/CES n 06/2018), para tal el estudio se utiliza del análisis documental para revelar los debates que precedieron su publicación y la concepción de formación en ellas presente. Constatamos que la fragmentación fue repaginada, se mantiene en la lógica destructiva del capital, así como la concepción de formación continua dirigida a la instrumentalización para el trabajo.

Palabras clave: Formación de Profesores. Directrices Curriculares. Educación Física.

Abstract: Aiming to analyze the fragmentation of formation in (new) National Curriculum Guidelines for undergraduate courses in Physical Education (Resolution CNE/CES n $n^{\circ}$ 06/2018), the study uses documentary analysis to reveal the debate leading up to your publication and the design of formation her present. We found that fragmentation was remodeled, keeps on destructive logic of capital, as well as the design of formation directed at exploitation for work.

Key words: Formation of Theachers. Curriculum Guidelines. Physical Education.

\section{Considerações iniciais}

Desde a promulgação da Resolução CNE/CP n 07/2004, quando se denominou de "consenso possível 3" o debate sobre a proposta de formação em Educação Física (EF) não foi tão acalorado como o que antecedeu o processo de reformulação das (novas) Diretrizes Curriculares Nacionais (DCN) para a formação do Graduado em EF. Analisando esse processo, Castellani Filho (2016) utiliza o termo "formação sitiada" para explicitar a tensão entre o setor conservador/corporativista e o setor progressista/revolucionário durante os trabalhos do Conselho Nacional de Educação (CNE) da Câmara de Ensino Superior (CES) sobre a reformulação do texto que culminou na Resolução CNE/CES no $06 / 2018$. 
Dentre o setor conservador/cooperativista podemos encontrar o Conselho Federal de Educação Física (CONFEF) e os Conselhos Regionais de Educação Física (CREFs) que, em se tratando da formação, sempre mantiveram o interesse em direcionar o campo da EF, isto fica evidenciado a partir dos estudos de Birk ${ }^{4}$ (2005), que analisou interesses e disputas no processo de formulação das diretrizes por meio das Comissões de Especialistas de Ensino em Educação Física (COESP-EF).

No setor progressista/revolucionário destacamos o Movimento Estudantil (MEEF), o Movimento Nacional Contra a Regulamentação do Profissional de EF (MNCR), o Grupo de Trabalho Temático (GTT) Formação Profissional e Mundo do Trabalho do Colégio Brasileiro de Ciências do Esporte (CBCE) e alguns grupos de pesquisas que defendem a formação única em licenciatura e consideram o eixo central da formação o trabalho pedagógico. Neste setor, destacam-se as cartilhas que o MEEF, por meio da Executiva Nacional de Estudantes de Educação Física (EXNEEF), lançou em 2009 sob o slogan "Educação Física é uma só. Formação Unificada Já! Pela revogação das atuais Diretrizes Curriculares" 5 . Neste documento, os estudantes explicitam que são contrários à divisão da formação, pois essa fragmentação não tem sustentação científica e não atende à realidade dos cursos, com isso, a entendem como um retrocesso e que tal divisão está pautada em interesses econômicos.

Sendo assim, as questões que se colocam neste trabalho são: o que determinou o debate para a definição das (novas) DCNEF? Como a Resolução CNE/CES no 06/2018, que instituiu as Diretrizes Curriculares Nacionais (DCN) dos cursos de graduação em EF, tratou a fragmentação da formação? Para tanto, no primeiro momento, trataremos de abordar as razões da decisão do Superior Tribunal de Justiça $(\mathrm{STJ})^{6}$, a qual proibiu o licenciado em EF de atuar em atividades que não são próprias da educação básica. No segundo momento, trataremos sobre a fragmentação repaginada da formação em EF que as (novas) DCN apresentam. Para tal, abordamos a concepção de formação relacionando-a com a pedagogia das competências e com a simetria invertida.

\section{Da decisão do STJ à publicação das (novas) DCNEF}

Vários movimentos ${ }^{7}$ provocaram a necessidade de o CNE iniciar o processo de reformulação da DCNEF, contudo, o ponto fulcral foi a decisão do STJ em 12 de novembro de 2014, com efeito de recurso repetitivo ${ }^{8}$. Na ocasião, o relator do processo no STJ, o Ministro Benedito Gonçalves, julgou que os cursos de graduação em licenciatura e bacharelado são distintos com disciplinas e objetivos particulares e determinou que o professor de EF que pretendesse atuar nos espaços formais e não formais de educação deveria concluir os dois cursos.

Esta decisão causou uma ebulição no campo da EF, pois muitos profissionais que haviam sido formados em cursos de licenciatura, cujos Projetos Pedagógicos de Cursos (PPC) garantiam a atuação em diferentes campos de intervenção profissional, desde então, passaram a ser proibidos de atuar como professores em academias, como personal trainer, técnicos desportivos ou agentes da saúde pública. Logo, os egressos de diferentes cursos se sentiram enganados pelas instituições de ensino superior e por seus 
professores, porém as instituições de ensino estavam apenas seguindo as determinações e encaminhamentos do CNE.

Nesse sentido, as instituições de ensino, professores, pesquisadores, movimentos sociais, grupos de pesquisa exigiram do CNE, responsável na legislação educacional, algum posicionamento a respeito. A partir de então, o próprio CNE, por meio da CES, manifestou-se a respeito, pois constantemente era consultado sobre esta questão e mantivera opinião contrária à dos ministros do STJ, como é possível observarmos nos pareceres CNE/CES 400/2005, CNE/CEB 12/2005 e CNE/CES 213/2003. A resposta à pressão que estava sofrendo, resultou numa Audiência Pública com o campo da EF realizada no dia 15 de outubro de 2015, nas dependências da PUC-GO, proferida pelo Conselheiro Paulo Barone. Ele frisou que "a instabilidade jurídica é absolutamente coorporativa e não de natureza acadêmica". Além disso, comentou que "o CONFEF interpreta as DCNEF erroneamente".

O conselheiro, ao tratar da EF, em particular, explicitou três princípios fundamentais que permeiam o campo: 1) a intervenção profissional do professor EF é um ato educativo, portanto, independentemente do campo de atuação profissional executa-se uma prática pedagógica no plano da cultura corporal; 2) as competências do egresso precisam ser articuladas no processo formativo, ou seja, é nos cursos de graduação que o estudante precisa enfrentar desafios de todas as naturezas da área da saúde pública, exercício físico, lazer, desporto, escola; e 3) unificar a formação em EF à licenciatura. A este último princípio, Paulo Barone comentou que talvez seria a solução para sanar os problemas da Educação Física e "[...] anunciou que havia uma comissão trabalhando na revisão das DCNs de Educação Física" (FURTADO et al., 2016, p. 782).

Em 11 de dezembro de 2015 houve a segunda Audiência Pública realizada na sede do CNE em Brasília, onde foi apresentada uma minuta de Resolução pela comissão de revisão9 das DCEEF com o objetivo de provocar o debate no campo da EF. A minuta ressaltou o fim da graduação na modalidade bacharelado, direcionando à formação única em licenciatura.

Os cursos de Bacharelado em Educação Física atualmente existentes entrarão em regime de extinção [...] As instituições de educação superior que mantêm cursos de Bacharelado em Educação Física poderão transformá-los em cursos de Licenciatura, elaborando novo projeto pedagógico [...] (BRASIL, 2015).

Logo anunciada a morte do bacharelado, entraram em cena mais uma vez os seus defensores, representados pelo seu principal mediador e articulador, o sistema Confef/Crefs, os quais delimitam os campos de atuação profissional em "escolares" - intervenção dos professores licenciados na escola - e "não escolares" - intervenção dos profissionais bacharéis nos demais espaços. O Confef, na Audiência Pública do dia 11 de dezembro daquele ano, exigia a formação de COESP para discutir o rumo da formação, uma proposta de repetir o que já acontecera com a promulgação da Resolução CNE/CES no 07, de 31 de março de 2004, uma estratégia que possibilitou ao Confef impor seu projeto de formação a partir de quatro elementos centrais: a ênfase nas competências, a questão do objeto de estudo, a concepção de ciência e a dicotomia licenciatura e bacharelado (TAFFAREL; SANTOS JÚNIOR, 2010).

O que podemos constatar no excerto: 
Professor Tojal inicia a sua fala declarando sua procedência como professor da UNICAMP, vice-presidente do CREF/CONFEF formado bacharel pelo parecer 215/87. Inicia estranhando que não tem uma Comissão de Especialista discutindo a questão da revisão das diretrizes e que não tem um documento prévio com o parecer, mas somente a Minuta de Resolução que eles tiveram acesso somente dia 7/12/2015, depois de enviar correspondência ao CNE forçando o convite para a Audiência ${ }^{10}$.

Importante ressaltar que em dezembro de 2015 deu-se início, na Câmara dos Deputados, cujo presidente à época era Eduardo Cunha, ao processo de impeachment da presidente Dilma Rousseff denunciada por crime de responsabilidade fiscal. Dava-se início ao golpe de Estado que levou à presidência da república Michel Temer (MDB). A conjuntura política do Brasil iria afetar também o campo da EF, pois a mudança também aconteceu no Ministério da Educação e, consequentemente, no CNE, o que provocou a desmobilização da comissão de revisão das DCNEF, sobretudo a saída do relator Paulo Barone - que nos últimos anos vinha acumulando conhecimentos sobre o problema da fragmentação da profissão EF. A partir de então, o processo de reformulação foi tratado apenas no interior do CNE, não houve mais nenhuma audiência pública e, ao que parece, os novos conselheiros ficaram sobre a pressão política promovida pelo Confef.

O fato é que em 18 de janeiro de 2018 a nova comissão ${ }^{11}$ promulgou as (novas) DCNEF, as quais são subsidiadas pelo Parecer CNE/CES 584/2018. Porém, a nova comissão não conseguiu ir na direção oposta às determinações do mercado de trabalho e aos ditames do movimento político do setor conservador/cooperativista, pois o bacharelado voltara de uma morte anunciada na minuta da resolução de 2015.

\section{As (novas) DCNEF e a repaginação da fragmentação da formação}

O problema que muitas instituições de ensino estavam enfrentando a partir dos questionamentos jurídicos sobre a formação que desenvolviam parecia estar sanado com a proposição de ingresso único no curso de graduação, porém, na metade do curso, concluída a dita "Formação Geral", o estudante deveria optar pelos "Conhecimentos Específicos" da licenciatura ou do bacharelado. Dessa forma, impôs-se a obrigatoriedade de todos os cursos do país ofertarem o curso de bacharelado e, com isso, abriram-se as portas para a repaginação da fragmentação da formação em EF no país.

Esta nova forma de organização dos currículos está posta no artigo $5^{\circ}$ da Resolução no 06/2018 (BRASIL, 2018, p. 1-2):

Art. $5^{\circ}$ Dada a necessária articulação entre conhecimentos, habilidades, sensibilidade e atitudes requerida do egresso para o futuro exercício profissional, a formação do graduado em Educação Física terá ingresso único, destinado tanto ao bacharelado quanto à licenciatura, e desdobrar-se-á em duas etapas, conforme descrição a seguir:

I - Etapa Comum - Núcleo de estudos da formação geral, identificador da área de Educação Física, a ser desenvolvido em 1.600 (mil e seiscentas) horas referenciais, comum a ambas as formações.

II - Etapa Específica - Formação específica a ser desenvolvida em 1.600 (mil e seiscentas) horas referenciais, na qual os graduandos terão acesso a conhecimentos específicos das opções em bacharelado ou licenciatura.

$\int 1^{\circ} \mathrm{No}$ início do $4^{\circ}$ (quarto) semestre, a Instituição de Educação Superior deverá realizar uma consulta oficial, por escrito, a todos os graduandos a respeito da escolha da 
formação que pretendem seguir na Etapa Específica - bacharelado ou licenciatura com vistas à obtenção do respectivo diploma, ou, ao final do $4^{\circ}$ (quarto) semestre, definir sua escolha mediante critérios pré-estabelecidos.

A saída encontrada para o empasse jurídico pelo CNE foi tirar a responsabilidade do Estado em garantir uma formação única e transferir para o estudante a escolha precoce de qual formação seguir, na medida em que é de responsabilidade individual a formação na dita "Etapa Específica". Assim, mantém-se a fragmentação da formação instituída no Brasil desde a promulgação da Resolução CFE no 03/1987, que segundo Taffarel e Santos Júnior (2010), é a estratégia do capital para desqualificar o trabalhador em seu processo de formação acadêmica inicial. Esta fragmentação tem correlação com a precarização do mundo do trabalho, mais precisamente ao que Alves (2007) definiu como "captura" da subjetividade do trabalhador, fruto da era da acumulação flexível e da integração orgânica com o trabalho coletivo. Portanto, entendemos que a proposição instituída pela Resolução CNE/CES no 06/2018 está submetida à exigência da formação de um novo trabalhador e associada à integração orgânica do capital.

Alves (2007, p. 187, grifo do autor) ressalta que a:

[...] integração "orgânica para o capital", aparece como "fragmentação sistêmica" da classe dos trabalhadores assalariados, isto é, "fragmentação" de consciência de classe contingente e de seus estatutos salariais com a constituição do precário mundo do trabalho a partir da proliferação dos contratos dos trabalhos atípicos.

Desta forma, percebemos o aprimoramento da relação capital/trabalho nas (novas) DCNEF, na medida em que contribui para uma formação de trabalhadores que possa fortalecer o modo de produção capitalista, adquirindo, a partir das exigências do mercado de trabalho, a capacidade e a habilidade de comunicação, abstração, raciocínio lógico, "dor de dono ${ }^{12 "}$ e tomada de iniciativa, mas longe da consciência de classe, pois não consegue resistir aos conflitos entre o capital e o trabalho. Sobre isso, Marx em sua obra de juventude de 1844, Manuscritos econômico-filosóficos, escreveu o seguinte: "o trabalhador se torna tanto mais pobre quanto mais riqueza produz, quanto mais a sua produção aumenta em poder e extensão" (MARX, 2010, p. 80). Isso reforça a ideia de que a proposta de formação apresentada para a EF no Brasil continua seguindo os ditames no modo de produção capitalista, haja vista que se mantém na lógica instrumentalista de formação.

Isso se revela nas duas áreas de conhecimento propostas no texto das (novas) DCNEF - Etapa Comum e Etapa Específica - mantendo-se muito próximo ao que foi elaborado pela COESP na primeira proposta das DCN para EF de 2004, pois esta, apesar de extinguir a dupla habilitação contida na Resolução CFE no 03/87 criando duas áreas de conhecimento na estrutura curricular - Conhecimento Identificador da Área (CIA) e Conhecimento Identificador do Tipo de Aprofundamento (CITA) -, acabou contemplando ainda mais a relação capital/trabalho com a dinâmica de aprofundamento ${ }^{13} \mathrm{em}$ diversas áreas como lazer, dança, esportes, ginástica, escola, dentre outras, privilegiando o bacharelado (VENTURA, 2005).

Assim, a Resolução CNE/CES no 06/2018 se mantém na lógica do capital e repagina a fragmentação da formação ao manter a diferenciação dos conteúdos programáticos na formação do licenciado e do bacharel, conforme está exposto em seus artigos $15^{14}$ e $18^{15}$. Essa é uma caraterística 
muito comum em um modelo neoliberal de formação de professores, cujas lógicas da pedagogia das competências e da simetria invertida prevalecem no desenvolvimento do currículo dos cursos de licenciatura. Podemos perceber os aspectos neoliberais na Resolução CNE/CES no 06/2018:

Art. $8^{\circ}$ A etapa comum deverá proporcionar atividades acadêmicas integradoras tais como:

b) disciplinas de aproximação ao ambiente profissional de forma a permitir aos estudantes a percepção acerca de requisitos profissionais, identificação de campos ou áreas de trabalho e o desenvolvimento de atividades didático-pedagógicas interativas com espaços profissionais, inclusive escolas de educação básica e média (BRASIL, 2018, p. 2, grifo nosso).

De acordo com Santos Júnior (2005) a pedagogia das competências na formação de professores é uma proposta de ensino que dá ênfase ao individualismo, porque o indivíduo é ensinado a se tornar o responsável por sua formação. O professor deve promover a competição entre os alunos por conta da corrida de acesso aos conhecimentos que darão ao futuro profissional a competência necessária para atuar de forma adequada às necessidades exigidas pelo mercado de trabalho. Desta forma, se alimentam os fetiches comuns da profissão, pois não se preocupa em explicar as múltiplas relações que o trabalho docente pode ter com o contexto social, desvirtuando e camuflando as contradições existentes na profissão professor.

Outra característica de uma educação baseada na pedagogia das competências é o rebaixamento dos conteúdos no ensino do professor, por meio do aligeiramento da formação e da flexibilização do currículo para atender a uma demanda quantitativa de profissionais, submetendo o desenvolvimento das competências ao modo de produção capitalista. Segundo Duarte (2006), uma proposta de ensino baseada na pedagogia das competências apresenta certa preocupação com o domínio teórico, mas substitui a centralidade dos conteúdos pela centralidade no método de aprendizagem; uma proposta que também valoriza os processos de ensino baseados no modelo de educação profissional, desenvolvidos por meio de conhecimentos operacionalizantes, comportamentais e atitudinais.

Consideramos que o caráter da formação acadêmica posto nas (novas) DCNEF também está baseado na simetria invertida, ou seja, o processo de formação dá-se a partir de valores hegemonicamente técnico-profissional por conta de sua relação com o desenvolvimento econômico capitalista. A formação profissional com base neste modelo obriga as instituições de ensino a relacionar, de forma pragmática, os conhecimentos curriculares à dinâmica comum de sala de aula, o que caracteriza a dita simetria invertida.

Para Mello (2000, p. 102):

[...] a formação do professor precisa tomar como ponto de referência, a partir do qual orientará a organização institucional e pedagógica dos cursos, a simetria invertida entre a situação de preparação profissional e o exercício futuro da profissão. As diretrizes que se seguem procuram avançar nessa característica, buscando tornar coerente a formação do professor com a simetria existente entre essa formação e o futuro exercício da profissão.

Logo, se o conhecimento mais valorizado da formação inicial é o advindo do cotidiano e pessoal, então, a formação deixa de abordar os conhecimentos mais desenvolvidos e ricos construídos pela humanidade ao longo de sua história. Mesmo quando é exigido algum tipo de conhecimento advindo 
do campo da ciência, este é substituído pelo conhecimento das competências e habilidades requeridas pela prática cotidiana (DUARTE, 2010). Esta é a lógica pautada na formação da Etapa Específica do professor/profissional de EF, modelo de educação que aprofunda o processo de fragmentação da área e está em consonância com a defesa do setor conservador/cooperativista da EF.

Outro aspecto que destacamos diz respeito aos objetos de estudos contidos nas (novas) DCEEF, restritos a apenas dois, os quais devem orientar os cursos no processo de (re)formulação de seus currículos.

A Educação Física é uma área de conhecimento e de intervenção profissional que tem como objeto de estudo e de aplicação a motricidade ou movimento humano, a cultura do movimento corporal, com foco nas diferentes formas e modalidades do exercício físico, da ginástica, do jogo, do esporte, das lutas e da dança, visando atender às necessidades sociais no campo da saúde, da educação e da formação, da cultura, do alto rendimento esportivo e do lazer (BRASIL, 2018, p. 1, grifo nosso).

A priori isso pode parecer um avanço, haja vista que na resolução anterior (CNE/CES n ${ }^{\circ}$ 07/2004) apenas um objeto de estudo era proposto, contudo, temos que considerar que o Parecer $\mathrm{CNE} / \mathrm{CP} \mathrm{n}^{\circ} 58 / 2004$ reconhecia diferentes termos e expressões utilizadas pela comunidade da EF, os quais definem diferentes objetos de estudo e de intervenção acadêmico-profissionais, como podemos aferir no excerto:

Entre os termos e expressões recorrentes na área, pode-se destacar: exercício físico, atividade física, movimento humano, atividade recreativa, atividade esportiva, atividade físico-esportiva, atividade corporal, cultura física, cultura do movimento, cultura do movimento humano, cultura corporal, cultura corporal de movimento, corporeidade, motricidade, entre outros (BRASIL, 2004, p. 7-8).

Portanto, as DCNEF de 2004 permitiam que as Instituições de Ensino Superior (IES) pudessem escolher outro objeto de estudo, já com a Resolução CNE/CES no 06/2018 isso deixou de ser possível, indicando apenas a motricidade ou movimento humano e a cultura do movimento corporal como objetos de estudos que devem servir de referências à formação do professor/profissional de EF no Brasil, os quais pressupõem sustentabilidade nas produções teóricas associadas às abordagens desenvolvimentista (TANI et al., 1988) e crítica emancipatória (KUNZ, 2006). A primeira, pode ser classificada como "teoria não crítica" (SAVIANI, 2006), já que busca compreender os condicionantes objetivos a partir do desenvolvimento motor. A última, apesar de adotar uma postura crítica da realidade, pois traz uma base teórica a partir dos estudos de Habermas, Paulo Freire e da Escola de Frankfurt, apresenta limites para o desenvolvimento de uma educação que promova a emancipação humana, pois, de acordo com os estudos de Taffarel e Morschbacher (2013), a emancipação humana só pode acontecer de maneira dialógica, por meio da ação comunicativa entre os sujeitos, ao invés da ruptura com a atual forma do capital organizar a vida.

Para essas autoras:

A emancipação não se dará fora de um violento processo de ruptura com o atual modo de o capital organizar a vida. E, portanto, a ontologia aponta a possibilidade teleológica da transição do socialismo ao comunismo. Mas sem aderência a esta realidade isto não é possível. Faz-se necessário anunciar, sim, o tipo de sociedade que se quer transformar a atual e com que instrumentos da luta de classes vamos contar para tal transição e 
revolução permanente. É neste marco conceitual que nos situamos (TAFFAREL; MORSCHBACHER, 2013, p. 62).

Corroborando com esse debate, Mészáros (2008) anuncia a incorrigível lógica da relação capital e educação sem mudança na sociabilidade social.

Poucos negariam hoje que os processos educacionais e os processos sociais mais abrangentes de reprodução estão intimamente ligados. Consequentemente, uma reformulação significativa da educação é inconcebível sem a correspondente transformação do quadro social no qual as práticas educacionais da sociedade devem cumprir as suas vitais e historicamente importantes funções de mudança (MÉSZÁROS, 2008, p. 25).

Contrários a todos esses aspectos que compõem o modelo de formação, compactuamos com o setor progressista/revolucionário da EF, o qual é favorável à presença de uma proposição de formação profissional contrária ao fortalecimento da pedagogia das competências e da simetria invertida. Desta forma, consideramos que a EF, tal como defendida por Taffarel et al. (2007, p. 46), deve ser caracterizada:

[...] historicamente pelo trabalho pedagógico da docência no campo da cultura corporal, ou seja, a atividade pedagógica no trato com o conhecimento da cultura corporal. Em qualquer campo de trabalho, seja de produção de bens materiais ou imateriais educação, lazer, saúde, competição de alto rendimento, produção de tecnologias esportivas e outros - a atividade pedagógica e o trato com o conhecimento da cultura corporal são as bases da formação acadêmica e do trabalho do professor de Educação Física. Isso aponta para a necessidade de considerarmos o princípio estruturação do conhecimento científico no currículo de formação de professores.

Por fim, uma "sólida formação teórica de base multidisciplinar e interdisciplinar na perspectiva da formação omnilateral" (TAFFAREL et al., 2007, p. 46) é um caminho possível, desde que possamos estar articulados e garantir nossa representatividade nas diferentes instâncias decisórias da política nacional e, principalmente, na constituição das propostas curriculares das Instituições de Ensino Superior (IES) espalhadas pelo Brasil. Nesse contexto, a mediação que poderá ser desenvolvida pela categoria dos professores destas instituições poderá a não concretude da proposta de formação que está posta nas DCNEF/2018, para isso, é necessário garantir espaços democráticos de debates e discussões nas instituições, espaços que promovam reflexões, socialização de diferentes produções acadêmicas nesse campo e que possibilitem a criação de estratégias, no sentido de criar uma resistência ao atual desenho curricular para a formação do professor de Educação Física. Para além disso, é necessário ainda estarmos articulados aos movimentos revolucionários que pautam a formação de caráter ampliado.

\section{Considerações Finais}

Este estudo tratou da repercussão da decisão do STJ sobre o problema da fragmentação na EF e a divulgação das (novas) DCN as quais se tornaram, a partir de dezembro de 2018, parâmetros para a reestruturação dos cursos de graduação em todo país. Um modelo de formação que repaginou a fragmentação da formação ao legitimar a dupla habilitação e obrigar as IES a oferecer as duas formações, apesar de ser por entrada única. Esta medida atende ao interesse mercadológico e acentua o rebaixamento teórico do futuro professor de EF. 
Constatamos que a conjuntura política que o país viveu entre os anos de 2016 e 2017 contribuiu para que houvesse uma repaginação da fragmentação da formação do professor/profissional de EF, haja vista que a Resolução CNE/CS n ${ }^{\circ}$ 06/2018 manteve-se atrelada aos interesses do setor conservador/corporativista. Esperamos que o setor progressista/revolucionário da EF se mantenha unido para o enfrentamento das tendências e conjunturas atuais, com a retomada do poder pela extrema direita, o que nos exige consciência e organização de classe e torna ainda mais presente e imperativa a célebre frase deixada por Marx e Engels (1998, p. 65) ao final do manifesto do Partido Comunista: "Proletários de todo os países, uni-vos!".

\section{Referências}

ALVES, G. Dimensões da reestruturação produtiva: ensaios de sociologia do trabalho. 2. ed. Londrina: Práxis, 2007.

BIRK, M. Interesses e disputas no processo de formulação das diretrizes curriculares nacionais para os cursos de graduação em educação física: as configurações das relações sociais. 2005. 365 f. Dissertação (Mestrado em Ciências do Movimento Humano) - Universidade Federal do Rio Grande do Sul, Porto Alegre, 2005.

BRASIL. Conselho Nacional de Educação. Define as Diretrizes Curriculares Nacionais para a formação inicial em nível superior (cursos de licenciatura, cursos de formação pedagógica para graduados e cursos de segunda licenciatura) e para a formação continuada. Resolução no 2 , de $1^{\circ}$ de julho de 2015. Brasília: Diário Oficial da União, 2 de julho de 2015, Seção 1, p. 8-12.

. Lei n. 9.394, de 20 de dezembro de 1996. Estabelece as Diretrizes e Bases da Educação Nacional. Brasília: Diário Oficial da União, 23 de dezembro de 1996.

Conselho Nacional de Educação. Diretrizes Curriculares Nacionais para a Formação de Professores da Educação Básica, em nível superior, curso de licenciatura, de graduação plena. Resolução CNE/CP no 1 de 18 de fevereiro de 2002. Brasília: Diário Oficial da União, 9 de abril de 2002. Seção 1, p. 31.

Conselho Nacional de Educação. Diretrizes Curriculares Nacionais para os cursos de graduação em Educação Física, em nível superior de graduação plena. Resolução CNE no 07, de 31 de março de 2004. Brasília: Diário Oficial da União, 5 de abril de 2004, Seção 1, p. 18.

Conselho Nacional de Educação. Diretrizes Curriculares Nacionais dos cursos de graduação em Educação Física e dá outras providências. Resolução CNE no 06, de 18 de dezembro de 2018. Brasília: Diário Oficial da União, 19 de dezembro de 2018, Seção 1, p. 48-49.

Conselho Nacional de Educação. Institui a duração e a carga horária dos cursos de licenciatura, de graduação plena, de formação de professores da Educação Básica em nível Superior. Resolução $\mathrm{CNE} / \mathrm{CP} \mathrm{n}^{\circ} 2$ de 19 de fevereiro de 2002. Brasília: Diário Oficial da União, 4 de março de 2002. Seção 1, p. 9.

Lei n ${ }^{\circ}$ 9.696, de 1 de setembro de 1998. Dispõe sobre a regulamentação da Profissão de Educação Física e cria os respectivos Conselho Federal e Conselhos Regionais de Educação Física. Brasília: Diário Oficial da União, 2 de setembro de 1998.

CASTELLANI FILHO, L. A formação sitiada diretrizes de educação física em disputa: jogo jogado? Revista Pensar a Prática, Goiânia, v. 19, n. 4, p., out./dez. 2016.

DUARTE, N. O debate contemporâneo das teorias pedagógicas. In: MARTINS, L. M.; DUARTE, N. (Orgs.). Formação de professores: limites contemporâneos e alternativas necessárias. São Paulo: Cultura Acadêmica, 2010. p. 33-49. 
DUARTE, N. Vigotski e o “aprender a aprender”: crítica às apropriações neoliberais e pós-modernas da teoria vigotskiana. Campinas: Autores Associados, 2006.

FURTADO, R. P.; VENTURA, P. R. V.; ANES, R. R. N.; PEDROZA, R. S.; FERRAZ JÚNIOR, I. N. Instabilidade jurídica e outras determinações: o CNE e a proposta de novas DCNs para a educação física. Revista Pensar a Prática, Goiânia, v. 19, n. 4, p., out./dez. 2016.

KUNZ, E. Transformação didático-pedagógico do esporte. 7. ed. Ijuí: Unijuí, 2006.

MARX, K. Manuscritos econômico-filosóficos. Tradução de Jesus Ranieri. São Paulo: Boitempo, 2010.

MARX, K.; ENGELS, F. O manifesto comunista. Tradução de Maria Lucia Como. Rio de Janeiro: Paz e Terra, 1998.

MELLO, G. N. de. Formação inicial de professores para a educação básica: uma (re)visão radical. São Paulo em Perspectiva, São Paulo, v. 14, n. 1, p. 98-110, 2000.

MÉSZÁROS, I. A educação para além do capital. 2. ed. São Paulo: Boitempo, 2008.

SAVIANI, D. Escola e democracia. 38. ed. Campinas: Autores Associados, 2006.

TAFFAREL, C. Z; LACKS, S; SANTOS JÚNIOR, C. de L; CARVALHO, M; D’AGOSTINI, A; TITTON, M; CASAGRANDE, N. Uma proposição de diretriz curricular para a formação de professores de educação física. In: TAFFAREL, C. Z; HILDEBRANDT-STRAMANN, R. (Orgs). Currículo e educação física: formação de professores e práticas pedagógicas nas escolas. Ijuí: Unijuí, 2007. p. 41-46.

TAFFAREL, C. Z; SANTOS JÚNIOR, C. de L. Formação humana e formação de professores de educação física: para além da falsa dicotomia licenciado x bacharelado. In: TERRA, D. V.; SOUZA JÚNIOR, M. (Orgs). Formação em educação física e ciências do esporte: política e cotidiano. Goiânia: Hucitec, 2010. p. 13-48.

TAFFAREL, C. Z.; MORSCHBACHER, M. Crítica a teoria crítica-emancipatória: um diálogo com Elenor Kunz a partir do conceito de emancipação humana. Revista Corpus et Scientia, Rio de Janeiro, v. 9, n. 1, p. 45-64, jan. 2013.

TANI, G. O.; MANUEL, E. de J.; KOKUBUN, E.; PROENÇA, J. E. de. Educação Física escolar: fundamentos de uma abordagem desenvolvimentista. São Paulo, EPU/Edusp, 1988.

VENTURA, P. R. V. Formação profissional em educação física: um desafio posto pelas diretrizes curriculares. Estudos, local, v. 32, n. 3, p., mar. 2005.

\footnotetext{
Notas:

${ }^{1}$ Universidade Federal do Pará. Doutorando em Educação pela Universidade Federal do Pará (UFPA), professor de Educação Física da rede estadual de ensino do Pará (SEDUC). Membro do Linha de Estudo em Educação e Pesquisa em Educação Física, Esporte e Lazer (LEPEL). ORCID: http:/ / orcid.org/0000-0002-9772-4413 Email: osvaldogaldino@hotmail.com

2 Doutor em Educação pela Universidade Federal do Pará (UFPA), professor de Educação Física da rede estadual de ensino do Pará (SEDUC). Membro do Linha de Estudo em Educação e Pesquisa em Educação Física, Esporte e Lazer (LEPEL). Docente da Faculdade de Educação Física Madre Celeste (ESMAC). ORCID: http://orcid.org/0000-0002-3204-9920 Email: robsonbastos@hotmail.com

${ }^{3}$ Universidade Federal do Pará. Foi o conjunto de mediações realizadas entre os setores que discutiam as DCNEF de 2004, com exceção do MEEF, que não coadunou com as determinações das diretrizes e retirou-se do processo.

4 A autora constatou o interesse do Confef em orientar as diretrizes para: 1) a qualidade de vida e promoção da saúde; 2) a regulamentação da profissão; e 3) a divisão entre licenciatura e bacharelado. Outro documento que reafirma este interesse no direcionamento da área é a Resolução Confef 046/02, que dispõe sobre a Intervenção Profissional de Educação Física, já que a própria Lei no 9.696/98 (BRASIL, 1998) não deixa claro o campo de atuação do "Profissional de Educação Física". Logo depois, o documento em questão serviu de subsídio para o Parecer CNE/CES 138/02 “[...] elaborado sob prestimosa assessoria do Confef'. (CASTELLANI FILHO, 2016, p. 760).

${ }_{5}^{5}$ Disponível em: < http://docs.wixstatic.com/ugd/1b4256 90ab5fc7db3e4a04aa77d130dc64d5a9.pdf>. Acesso em: 10 fev. 2019.

6 Recurso especial N. 1.361. 900-SP (2013/0011728-3). Disponível em: <
https://ww2.sti.jus.br/docs internet/revista/eletronica/sti-revista-eletronica-2014 236.pdf >. Acesso em: 06 fev. 2019.
} 
7 O debate da EF há algum tempo tem-se concretizado também na esfera jurídica. A exemplo, está a Ação Civil Pública N. 2913490.2013.01.3900 de 28 de janeiro de 2014, Seção Judiciária do Pará, que suspendeu a restrição ao campo de atuação dos profissionais graduados em licenciatura, por entender que a Lei n ${ }^{\circ}$ 9.696/98 não prevê distinção entre licenciados e bacharéis.

8 Segundo Furtado et al (2016, p. 782) “[...] trata-se de um dispositivo jurídico, que deveria destinar-se a teses jurídicas com fundamentações idênticas em questão de direito. Todos os Estados que tinham assegurado via decisões de primeira e segunda instâncias o direito ao exercício profissional, perderam esta condição após a decisão do STJ de 12 de novembro 2014".

${ }_{9}$ Composta pelos Presidente Conselheiro Luiz Roberto Liza Curi, Relator Conselheiro Paulo Monteiro Vieira Braga Barone e pelo Membro da Comissão Conselheiro Yugo Okida.

10 Relato da Audiência Pública proferido pela professora Celi Taffarel. Disponível em: <http://www.rascunhodigital.faced.ufba.br/ver.php?idtexto=224>. Acesso em: 10 fev. 2019.

${ }^{11}$ Composta pelos Conselheiros: Antônio de Araújo Freitas Júnior (Presidente), Luiz Roberto Liza Curi (Relator), José Loureiro Lopes, Yugo Okida e Márcia Ângela da Silva Aguiar.

12 Expressão cada vez mais usada no meio corporativo para expressar o sentimento de pertença de um indivíduo que cuida de algo que não é seu, mas é como se fosse. Esse tipo de profissional é a mais procurado atualmente no mundo do trabalho pelos capitalistas.

${ }^{13}$ Esta foi a ideia do 3+1 na EF - 3 anos de estudos de conhecimento básico e 1 ano de aprofundamento nas diversas áreas de interesses.

14 Art. 15. Os cursos de Licenciatura em Educação Física, respeitadas a diversidade nacional e a autonomia pedagógica das instituições, devem garantir uma formação profissional adequada aos seguintes conteúdos programáticos: a) Política e Organização do Ensino Básico; b) Introdução à Educação; c) Introdução à Educação Física Escolar; d) Didática e metodologia de ensino da Educação Física Escolar; e) Desenvolvimento curricular em Educação Física Escolar; f) Educação Física na Educação Infantil; g) Educação Física no Ensino Fundamental; h) Educação Física no Ensino Médio; i) Educação Física Escolar Especial/Inclusiva; j) Educação Física na Educação de Jovens e Adultos; e k) Educação Física Escolar em ambientes não urbanos e em comunidades e agrupamentos étnicos distintos (BRASIL, 2018, p. 4).

15 Art. 18. [...] a formação do Bacharel em Educação Física deverá [...] ser concebida, planejada, operacionalizada e avaliada, qualificando-o para a intervenção profissional em treinamento esportivo, orientação de atividades físicas, preparação física, recreação, lazer, cultura em atividades físicas, avaliação física, postural e funcional, gestão relacionada com a área de Educação Física, além de outros campos relacionados às prática de atividades físicas, recreativas e esportivas [...] (BRASIL, 2018, p. 5).

Recebido em: 30.11 .2019

Publicado em: 20.04.2020 